\title{
A racionalização do trabalho dos assistentes sociais do INSS
}

\author{
Fernanda de Oliveira Prado \\ Universidade Estadual de Londrina (UEL)
}

\author{
Evaristo Emigdio Colmán Duarte \\ Universidade Estadual de Londrina (UEL)
}

\section{A racionalização do trabalho dos assistentes sociais do INSS}

Resumo: O presente artigo examina a influência da racionalização sobre os processos de trabalho dos assistentes sociais que atuam na Política de Previdência Social, especificamente no Instituto Nacional do Seguro Social (INSS). A pesquisa teve por base os dados coletados através de questionários aplicados a um determinado grupo de assistentes sociais que trabalhavam em Agências da Previdência Social do INSS e a análise de suas rotinas de trabalho. A análise constatou que no INSS a implantação de mecanismos de racionalização do trabalho dos assistentes sociais encontra-se em estágio avançado, os quais têm sido utilizados para aumentar a produtividade dos profissionais e também para restringir o acesso dos trabalhadores aos seus direitos.

Palavras-chave: Serviço Social. Racionalização do Trabalho. Previdência Social. INSS.

\section{The Rationalization of Work of Social Workers at INSS}

Abstract: This article examines the influence of rationalization on the activities of social workers who implement social security policy, specifically at the National Social Security Institute (INSS). The study is based on data collected through questionnaires given to a particular group of social workers who serve at the social security agencies of the INSS and an analysis of their work routines. The analysis found that at INSS the implementation of mechanisms for the rationalization of the tasks of the social workers is at an advanced stage, and has been used to increase the productivity of professionals and to restrict workers access to their rights.

Keywords: Social Work. Rationalization of Labor. Social Security. INSS. 


\section{Introdução}

Quando falamos em processo de trabalho em sua forma genérica, temos em mente os elementos fundamentais que compõem todo o trabalho, ou seja, objeto, meios de trabalho, a atividade ou o próprio trabalho. Todo processo de trabalho em sua forma abstrata é composto por esses elementos. O que de fato irá distinguir o trabalho nas diferentes épocas não é o que se produz, mas como se produz, isto é, quem produz, quem se apropria e como se distribui o que é produzido (MARX, 1996).

Partindo disso, para estudar o processo de trabalho do assistente social no INSS na atualidade precisamos compreender com que finalidade o Estado organiza o trabalho dos servidores na Política de Previdência Social. Para tanto, faremos um breve resgate da Política de Seguridade Social a partir da Reforma do Estado, sobre o Serviço Social no INSS nas duas últimas décadas, e sua influência sobre os processos de trabalho dos assistentes sociais do INSS, com destaque para as ferramentas de racionalização do trabalho.

\section{Crise do Capital e a Reforma do Estado}

O capitalismo tem como uma de suas características imanentes a ocorrência de crises cíclicas, as quais decorrem da lei geral de acumulação e provocam a concentração e centralização de capitais. Uma dessas crises irrompeu a partir de 1929, sendo o seu ápice a quebra da bolsa de Nova Iorque. Naquela conjuntura, as medidas implementadas pelos principais estados capitalistas para enfrentar a crise foram caracterizadas pela expansão da produção, associada à ampliação do consumo através das políticas conhecidas pelo binômio fordismo/keynesianismo. Como consequência, cresceram os empregos e alargaram-se as políticas sociais, pois as iniciativas de inspiração keynesiana coincidiram com a monumental destruição de forças produtivas provocadas pela Segunda Guerra mundial.

Porém esgotado este modelo de gestão da crise, que propiciou um crescimento sem precedentes do capitalismo, uma nova crise se alastra a partir da década de 1970, dessa vez em uma conjuntura que exige medidas diferentes daquelas aplicadas pelos capitalistas nos trinta anos anteriores. As novas ferramentas adotadas receberam a denominação de neoliberais, pois restringiram as medidas estatais de estimulo à reprodução da força de trabalho, recolocando o tratamento dado pelo liberalismo clássico à sobrevivência das classes trabalhadoras.

Observa-se então que diante da crise, os estados capitalistas recorrem a mudanças no sistema com o objetivo de impedir a queda da taxa de lucro. Sempre que os ganhos são ameaçados, as burguesias procuram estratégias para manter a acumulação de seus capitais. Essas estratégias alteram os processos de trabalho independentemente do tipo de vínculo empregatício do trabalhador. É preciso destacar que o Estado é peça fundamental nesse processo. Várias medidas aqui citadas, adotadas para superação da crise, dependem da direta atuação do Estado. Seja através do gerenciamento das políticas sociais ou da ampliação ou retração dos direitos, tudo passa pelo âmbito do Estado. Isso ocorre porque ele não é apenas um acessório utilizado pelo capital, mas o principal meio para dar continuidade a esse sistema. De acordo com Marx, no capitalismo o Estado representa o comitê executivo da burguesia, ou seja, representa a classe dominante, a qual se utiliza do Estado para resolver os seus negócios.

Sendo assim, quando esta crise afetou o Brasil, no fim da década de 1980, o Estado imediatamente implantou os mecanismos neoliberais a partir das orientações dos órgãos financeiros internacionais, dos empresários vinculados ao grande capital e da burocracia estatal a eles associadas (MOTA, 1995). Iniciou-se então, por iniciativa do governo FHC, um movimento em defesa da Reforma do Estado visando pôr fim a denominada crise com a alegação de que a intensa intervenção estatal, que se deu durante o Estado de Bem-Estar ${ }^{1}$, levou o Estado brasileiro a uma sobrecarga de demandas e por isso era indispensável à adoção de medidas para diminuir gastos “desnecessários” (BRASIL, 1995).

As medidas mais contundentes implantadas pelo governo foram os cortes do orçamento público e as restrições de direitos. Entretanto, dentre as medidas neoliberais estão também àquelas vinculadas às mudanças nos processos de trabalho. Exemplo disso foram as mudanças no gerenciamento da força de trabalho proposta pela Reforma do Estado sob o argumento de modernização. De acordo com o Plano Diretor (BRASIL, 1995) que norteou a Reforma, era necessária uma transição do modelo burocrático para o gerencial no que se refere à gestão da força de trabalho:

A administração pública gerencial constitui um avanço e até certo ponto, um rompimento com a administração pública burocrática. Isto não significa, entretanto, que negue todos os seus princípios. Pelo contrário, a administração pública gerencial está apoiada na anterior, a qual conserva, embora flexibilizando, alguns dos seus princípios fundamentais, como a admissão segundo rígidos critérios de mérito, a existência de um 
sistema estruturado e universal de remuneração, as carreiras, a avaliação constante de desempenho, o treinamento sistemático. A diferença fundamental está na forma de controle, que deixa de basear-se nos processos para concentrar-se nos resultados, e não na rigorosa profissionalização da administração pública, que continua um princípio fundamental.

Nesta lógica, as propostas da Reforma Administrativa e Previdenciária, no fim da década de 1990, além de tratarem de uma série de corte de direitos dos trabalhadores, definidas pouco antes na Constituição Federal, também indicaram mudanças nos padrões de gestão do INSS. Nos anos de 2002 e 2003, sob a coordenação do então secretário executivo Carlos Eduardo Gabas, essas medidas ganharam notoriedade, mas foi a partir de 2005, quando Nelson Machado assumiu o Ministério da Previdência Social, que elas foram devidamente implantadas (DATAPREV, 2013).

\section{Racionalização do Trabalho}

Desde o momento em que o modo de produção capitalista se assenhoreou das formas de produção, quando ingressou na fase da grande indústria, os capitalistas se dedicaram a estudar os processos de trabalho para inventar melhores formas de extração da mais valia. Ficou evidente, que o primeiro passo para a obtenção de maiores resultados sobre o trabalho seria retirando das mãos do trabalhador o controle sobre este processo. Conforme Braverman (1976) é deste modo que surgiu a gerência científica ou racionalização do trabalho, a qual se tornou uma ferramenta do capital no estudo do trabalho com o objetivo de obter o controle sobre os processos de trabalho para que assim, o capitalista, comprador da força de trabalho, incrementasse a extração de mais-valia. O eixo central da gerência é o conceito de controle. Logo, para aplicação dos princípios de racionalização do trabalho é de suma importância que o primeiro passo seja extrair do trabalhador qualquer decisão sobre o trabalho. De acordo com Braverman (1976, p. 94), "o controle sobre o processo de trabalho deve passar às mãos da gerência, não apenas num sentido formal, mas pelo controle e fixação de cada fase do processo, inclusive seu modo de execução".

Contudo, para que o controle seja aplicado, há três princípios que precisam ser desenvolvidos ao longo do processo. Estes são definidos por Braverman (1976) como: a expropriação do conhecimento; a centralização do conhecimento; e a definição da execução do trabalho. Em resumo, o conhecimento extraído e centralizado é utilizado para controlar cada momento do processo de trabalho e a forma de sua execução. Esse movimento descrito por Braverman (1976) determina todo o desenvolvimento dos processos de trabalho na lógica capitalista e, portanto, permeia os mais diversos espaços ocupacionais, tanto públicos quanto privados.

No contexto da racionalização na Previdência Social, o processo é mais recente. Foi só a partir do fim da década de 1990 que a direção do INSS passou a estudar com afinco as possibilidades de implantação das medidas de controle do funcionalismo público.

A Previdência Social foi uma das primeiras instituições públicas atingida por estas medidas, e por isso já nos anos 2000 começa a ser arquitetado o projeto de modernização da previdência. Apesar da racionalização do trabalho ter origem na necessidade de aumentar a exploração - controlar gastos, restringir direitos -, a justificativa apresentada à sociedade para o desenvolvimento do novo projeto era o de diminuir as extensas filas que a população formava nas agências da Previdência Social em busca de atendimento e no combate às fraudes que, com frequência, eram notícia na mídia impressa e televisiva. Foi a partir desses elementos e, imbuídos do discurso de "foco no cidadão e humanização do atendimento", que as novas medidas foram colocadas em prática na instituição: "Para dar 'resolutividade' a esta gigantesca demanda, ou seja, para que o cidadão consiga acessar os seus direitos, é necessária uma atenção constante ao atendimento - aos processos de gestão, ao acompanhamento de metas, às tecnologias envolvidas, às dimensões do quadro de pessoal, às políticas de futuro" (DATAPREV, 2013, p. 8).

De acordo com o documento publicado pela Dataprev (2013), as medidas previstas no projeto de modernização baseavam-se em três eixos: mudanças organizacionais; gestão de pessoas e de processos; melhoria das tecnologias de informação.

Referente às mudanças organizacionais, foram realizadas dois tipos de ações: segundo a diretoria do INSS, a primeira alteração remete ao organograma da instituição visando reduzir a distância entre a alta hierarquia e os trabalhadores da linha de frente. A segunda previa a incorporação dos setores de arrecadação e fiscalização previdenciária à estrutura da Receita Federal, tornando o INSS responsável apenas pela concessão e manutenção dos benefícios.

Sobre a gestão de pessoas e de processos, definidos como a "busca de conciliar incentivos ao desempenho com oportunidades para desenvolvimento profissional e fortalecimento dos mecanismos meritocráticos de 
ascensão profissional" (DATAPREV, 2013, p. 36,), implantou-se a profissionalização da gestão, ou seja, orientação dos processos de trabalho com foco nos resultados utilizando-se dos critérios de mérito, mensuração de resultados, entre outros aspectos destinados para incentivar os trabalhadores no alcance dos resultados e assim dar maior eficiência ao sistema.

Por fim, como o próprio nome diz, o terceiro eixo tem como fundamento a melhoria das tecnologias de informação, ou seja, a melhoria dos sistemas informatizados e criação de novos para informatizar todas as etapas do processo de trabalho. A informatização da Previdência Social é realizada pela empresa Dataprev.

A partir de tais premissas, várias ferramentas foram implementadas e constantemente aprimoradas com vistas a alcançar os objetivos propostos pelo Projeto de Modernização da Previdência Social. A seguir descreveremos as mudanças de maior relevância e impacto na vida dos trabalhadores que ocorreram após o início da aplicação das medidas que consideramos:

1- Sistemas informatizados: estes têm sido uma das ferramentas com maior investimento ao longo dos anos no INSS. Atualmente eles não apenas processam informações dos segurados da previdência e seus benefícios, mas controlam toda a execução do trabalho dos trabalhadores da instituição mediante o controle da duração de cada atendimento prestado, da quantidade de atendimentos realizados durante a jornada de trabalho, do alcance de metas institucionais e do registro de entrada e saída diária da jornada de trabalho;

2- O aumento da jornada de trabalho: em 2009 a jornada de trabalho do servidor passou de seis para oito horas diárias. Posteriormente, diante de muita pressão da categoria implantou-se o sistema ininterrupto de atendimento, caracterizado pela realização de dois turnos de seis horas diárias cada um. Entretanto, para que os servidores tenham direito a este benefício cada Agência da Previdência Social (APS) precisa estar dentro das metas impostas pela instituição. A cada seis meses, cada APS é reavaliada e caso não tenha cumprido as metas perde o direito a realização dos turnos de seis horas. Caso a APS atinja novamente as metas, pode ou não ter reestabelecido o turno de seis horas, tudo irá depender da gerência que pode decidir pela execução ou não da jornada diferenciada;

3- Implantação de sistema de gratificação vinculado ao cumprimento de metas institucionais e ao desempenho individual: as APS precisam cumprir semestralmente metas previamente definidas no plano de ação institucional. Caso não as cumpram pode haver um impacto sobre a remuneração do servidor com o desconto de uma porcentagem do valor pago. Há ainda a gratificação de desempenho individual, que submete cada servidor a uma avaliação semestral por parte da gerência da APS, avaliando-se sua assiduidade, desempenho, colaboração e etc.

Como podemos ver todas as gratificações ou prêmios concedidos aos trabalhadores exigem, como contrapartida, o cumprimento de metas, na maioria das vezes abusivas e impossíveis de ser atingidas. Os bônus nada mais são que ferramentas utilizadas para obter o controle do trabalho e assim extrair cada vez mais dos trabalhadores com um número menor de servidores. Veremos a seguir como isso tem influenciado o trabalho dos assistentes sociais.

\section{Serviço Social na Previdência Social}

O período de 1930 em diante foi marcado pelo início de sucessivas intervenções estatais no sentido de criar um sistema de proteção social no Brasil ${ }^{2}$. Tratava-se da preparação do Estado para efetivar a transição do país do modelo pré-capitalista agrário ${ }^{3}$, vigente até aquele momento, para um modelo capitalista de fato. Para isso foi imprescindível criar políticas e serviços que permitissem a reprodução da força de trabalho em moldes capitalistas, necessários às mudanças que viriam a ocorrer. Nesta conjuntura, segundo Prado (2014, p. 17), os serviços previdenciários são os que mais cresceram:

De todas as intervenções estatais relativas à proteção social, as mais expressivas vão ocorrer no âmbito da previdência social, a qual, em 1933, ganha uma estrutura administrativa através da criação dos Institutos de Aposentadorias e Pensões - IAPS. Estes Institutos, caracterizados por autarquias centralizadas no governo federal e supervisionadas pelo Ministério do Trabalho Indústria e Comércio, representavam a unificação das Caixas de Aposentadorias e Pensões - CAPs - dos trabalhadores de diversas categorias criadas ainda na década de 20 e que foram sendo substituídas gradativamente. Ambas, tanto CAPs quanto IAPs, vão sendo incorporadas ao sistema de forma seletiva e fragmentada, conforme sua expressividade e importância para o desenvolvimento econômico do país.

Neste contexto de mudanças políticas e econômicas e de expansão das políticas e serviços sociais é que nasceram também as primeiras Escolas de Serviço Social no Brasil, e a profissão começou a se 
consolidar no cenário brasileiro, sendo que a Previdência Social foi um dos primeiros espaços ocupados pelos novos profissionais.

Oficialmente, o Serviço Social é instituído na Previdência Social em 1944, quando foi emitida a portaria $\mathrm{n}^{\circ}$ 52, de 06 de setembro do referido ano, pelo Conselho Nacional do Trabalho (CNT) (MOREIRA, 2005; ROZENDO, 2010; YASBECK, 2008). Esta portaria autorizou a organização de um setor de Serviço Social para atuar junto a demandas do CNT com relação a concessão de benefícios por parte dos Institutos e Caixas de Aposentadorias e Pensões.

Daí em diante, conforme surgiram novas demandas relativas aos benefícios e serviços, o Serviço Social ganhou novos espaços e se consolidou na estrutura previdenciária. Assim como o surgimento do Serviço Social decorreu de uma mudança de maior amplitude, a história da profissão na instituição se desenhou conforme ocorreram mudanças político-econômicas e sociais no país ${ }^{4}$.

Ao ingressar na década de 1990 múltiplos acontecimentos influenciaram o trabalho do assistente social, principalmente àqueles decorrentes da necessidade de adaptação do capital, para enfrentar a crise. Desse modo, redefiniram-se estratégias para manutenção dos lucros fundamentada no ideário neoliberal. Por isso, o processo apresentado por Raichellis $(2009$, p. 6), como reestruturação produtiva, "repercute no campo profissional tanto nos sujeitos com os quais o Serviço Social trabalha - os usuários dos serviços sociais públicos - como também no mercado de trabalho dos assistentes sociais que, como o conjunto dos trabalhadores, sofre o impacto das mudanças que atingem o exercício profissional".

Poderíamos acrescentar ainda que neste contex to o retraimento do Estado que levou a mudanças no perfil das políticas sociais, com o objetivo de diminuir os gastos públicos para favorecer cada vez mais o capital, provocou a alteração dos processos de trabalho, os quais se tornaram cada vez mais padronizados, controlados, "enxutos", ou seja, foram racionalizados. Assim as modalidades de controle do trabalho, aperfeiçoaram-se cada vez mais dentro do serviço público, porém sempre sob o discurso da eficiência e eficácia.

Além das mudanças conjunturais, especificamente com relação ao Serviço Social estava em curso um processo de rediscussão das bases conceituais da profissão. Uma das principais discussões foi a transição da compreensão do fazer profissional enquanto prática, entendida apenas como atividades executadas pelo profissional para a concepção de trabalho. Esta mudança não alterou apenas uma terminologia, mas definiu que o fazer profissional não correspondia apenas às ações executadas pelo profissional independente da realidade no qual está inserido. Compreender o Serviço Social enquanto trabalho, segundo Iamamoto (2001), é passar a compreender a ação profissional vinculada com a sua realidade, é considerar que tanto os elementos internos - que correspondem ao desempenho profissional - quanto os externos - que se relacionam à realidade social na qual o profissional desempenha sua atividade tem influencia direta no exercício da profissão.

De acordo com essa abordagem, não basta a definição do que é ou do que deve fazer o assistente social. Em cada espaço ocupacional os profissionais devem responder às demandas impostas pela instituição e pela sociedade, e enfrentar o conjunto de relações de forças políticas e econômicas envolvidas neste processo. Deste modo, a atuação profissional não pode ser pensada como algo pré-determinado, pois ao se defrontar com a realidade vamos de encontro com uma riqueza de situações que interferem no fazer profissional, como por exemplo, a racionalização. Trata-se do que, em outras palavras, parece indicar Netto (2005, p. 68): "O caminho da profissionalização do Serviço Social é, na verdade, o processo pelo qual seus agentes - ainda que desenvolvendo uma autorrepresentação e um discurso centrados na autonomia dos seus valores e da sua vontade - se inserem em atividades interventivas cuja dinâmica, organização, recursos e objetivos são determinados para além do seu controle".

Ou seja, por mais que exista um projeto profissional, no caso do Serviço Social um projeto ético-político, que expresse os anseios e valores dos profissionais, quando eles entram em contato com a realidade precisam interagir com as determinações institucionais que na maioria das vezes não estão na mesma direção da profissão. Enquanto trabalhadores que vendem sua força de trabalho, os profissionais precisam se sujeitar às determinações daquele espaço ocupacional específico. Uma destas determinações é o processo de racionalização. Delgado e Aquino (2014), ao analisar o alto índice de informalidade dentro do Serviço Social, atribuem tal característica à gestão que visa resultados, eficácia e eficiência da administração dos recursos e financiamentos, seja em âmbito privado, público estatal o que demonstra mais uma vez uma tendência à racionalização em geral no Serviço Social.

A partir da compreensão deste contexto de mudanças macroeconômicas e específicas do Serviço Social é que devemos analisar o trabalho do assistente social a partir da década de 1990, período em que se iniciam as principais mudanças com relação à racionalização dos processos de trabalho as quais ainda se fazem presentes na atualidade. 


\section{Pesquisa realizada}

Neste artigo nos limitaremos a examinar a influência das ferramentas de racionalização sobre o trabalho dos assistentes sociais. Os resultados aqui apresentados baseiam-se em pesquisa desenvolvida como parte de uma Dissertação de mestrado apresentada ao Programa de Pós-graduação em Serviço Social e Política Social da Universidade Estadual de Londrina. Tinha por objetivo fazer uma análise preliminar dos processos de trabalho dos assistentes sociais do INSS, tendo como público alvo os profissionais assistentes sociais que atuam em diversas Agências da Previdência Social de uma determinada Gerência Executiva (GEX) do INSS, localizada no sul do país.

Os dados da pesquisa foram obtidos em duas etapas: a primeira constituiu-se da coleta de informações sobre a rotina de trabalho dos 14 assistentes sociais lotados nas APS, no formato de planilha dividida por dia e horário, visando reproduzir a rotina diária dos assistentes sociais em sua jornada de trabalho; na segunda etapa procedemos com a aplicação de um questionário para um assistente social de cada APS, com questões abertas e fechadas, em busca de compreender a percepção destes acerca dos seus processos de trabalho. Tal instrumento estava fundamentado na Lei de Regulamentação da Profissão (BRASIL, 1993), na Matriz Teórico Metodológica do Serviço Social (BRASIL, 1994) e no Manual Técnico do Serviço Social (DIRSAT, 2012). Foram abordadas questões relativas ao exercício profissional levando em consideração metas institucionais, ferramentas de gestão e o próprio desenvolvimento do trabalho.

A única exigência para participação na pesquisa é que os sujeitos deveriam atuar diretamente no Serviço Social $^{5}$. Além disso, não participaram da coleta de dados a própria pesquisadora, que faz parte da equipe de Serviço Social, a representante técnica da equipe que ocupa cargo de chefia na GEX e um dos assistentes que, por motivos particulares, optou pela não participação.

Observando cada tabela dos profissionais ficou evidente que há divisão de tarefas em todas as agências, com horários para início e fim das ações e programação específica para cada dia ou período da jornada de trabalho do assistente social. Algumas atividades tem um tempo pré-determinado, igual para todas as APS, para execução das ações, como é o caso da avaliação social que tem duração estabelecida em sessenta minutos.

É preciso considerar que as atividades que compõem as metas institucionais, e por isso tem impacto nos indicadores da instituição e consequentemente na remuneração mensal dos trabalhadores, podem ser priorizadas em detrimento de outras atividades, ou seja, a Reabilitação Profissional e os Projetos desenvolvidos pelo Serviço Social podem ser deixados de lado quando há a necessidade de adequar àquelas ações previstas nas metas institucionais, como é o caso da Avaliação Social que hoje é a principal demanda da instituição para o Serviço Social.

A partir da análise da rotina dos assistentes sociais, naquele dado momento, observou-se que a maior parte das ações, ou seja, 39\% da jornada de trabalho era voltada à Avaliação Social do Benefício de Prestação Continuada (BPC), 24\% à Reabilitação Profissional, 15\% à Habilitação de Benefícios, e $13 \%$ a atividades não específicas, que podem ser uma orientação, atendimento não agendado, conclusão de atividades ou pendências administrativas; apenas 9\% para desenvolvimento dos projetos do Serviço Social.

Importante ressaltar que quando a coleta de dados foi feita os assistentes sociais ainda realizavam a habilitação do $\mathrm{BPC}^{6}$, a qual durante o processo de conclusão da pesquisa

Tudo se organiza de forma a diminuir cada vez mais o tempo para cada tarefa e assim estabelecer um padrão a ser aplicado a todos os trabalhadores, permitindo que se faça cada vez mais em menos tempo, independentemente do que isso implica para o trabalhador ou para quem procura o serviço. foi retirada da agenda dos assistentes sociais. Tal fato ocorreu devido a uma nova conjuntura e de correlação de forças que permitiu a substituição da habilitação por outras atividades previstas para desempenho do assistente social desde que em conformidade com a demanda de cada APS. Houve agências que precisaram abrir mais vagas para avaliação social ${ }^{7}$ do BPC, outras aumentaram os dias de atendimento da Reabilitação Profissional ${ }^{8}$, e há aquelas em que foi possível ampliar o rol de atividades com o início da elaboração e da execução de projetos do Serviço Social previstos nos documentos técnicos que norteiam o trabalho dos assistentes sociais na instituição.

Podemos destacar ainda, que as agendas dos profissionais são definidas de acordo com a demanda institucional. Por exemplo, APS de maior porte, que ficam localizadas em cidades com maior volume de 
atendimentos, tem maior procura por avaliação social do BPC e, portanto, necessitam de maior oferta de vagas deste serviço. Em contrapartida, municípios menores possuem um número menor de atendimentos ou procura por determinados serviços e por isso possuem maior possibilidade de executar ações além da Avaliação Social do BPC e Reabilitação Profissional.

Com relação ao desenvolvimento destes projetos, sabemos que há grande dificuldade dos profissionais executarem tais ações, pois são atividades de natureza qualitativa, não quantificáveis e, portanto, de difícil mensuração e controle, o que permite ao profissional maior controle do processo de trabalho. Segundo Braverman (1976, p. 104): "Porque, se a execução dos trabalhadores é orientada por sua própria concepção, não é possível como vimos, impor-lhes a eficiência metodológica ou o ritmo de trabalho desejado pelo capital". Por isso, não é de se estranhar que um espaço que adotou os princípios da gerência e racionalização do trabalho, não priorize ou não permita a execução dessas atividades, que muitas vezes passam a ser combatidas ou até mesmo descartadas pela instituição.

Com relação ao questionário aplicado, em quatro questões, através de abordagens distintas, indagamos a possibilidade dos assistentes sociais participarem de atividades que incluíam desde o planejamento das atividades até sua execução tais como: planejamento, execução e avaliação de pesquisas sociais; elaboração, coordenação, execução e avaliação de planos, programas e projetos que sejam do âmbito de atuação do Serviço Social com participação da sociedade civil; elaboração, implementação, execução e avaliação de políticas sociais; planejamento, organização e administração de benefícios e Serviços Sociais.

Nas quatro questões os assistentes sociais, com exceção de dois profissionais, responderam que não participavam deste tipo de atividades. Entretanto, os que responderam que participavam colocaram uma observação de que estavam envolvidos apenas na execução dessas atividades. A partir do conhecimento que possuímos sobre a realidade do trabalho dos sujeitos que responderam ao questionário acreditamos que os assistentes sociais que responderam à pergunta dizendo que não participavam daquele tipo de atividade tinham em mente o fato de só atuarem na execução da política e, portanto, não consideraram que participavam de todas as etapas do processo.

Nas quatro questões nota-se que de modo geral os profissionais consideram que atuam apenas na execução das ações o que caracteriza que há uma centralização dos processos de planejamento nos níveis gerenciais, uma das características da racionalização do trabalho.

Isto indica que no INSS adota-se o modelo de gestão baseado na racionalização, de acordo com o qual, o controle é monopolizado pela alta gerência. Por isso as atividades são racionalizadas ao máximo, atribuindo aos profissionais meras funções executivas. Do ponto de vista do capital, é exatamente para isto que o Serviço Social é demandado, ou seja, para exercício das funções executivas que lhe são conferidas. Conforme Netto (1996, p. 70), o Serviço Social "é uma variável da idade do monopólio", que enquanto profissão nasce e se funda neste contexto, e os profissionais são requeridos para atuar como "agentes executores das políticas sociais".

Em outras duas questões, abordamos sobre a possibilidade de realização do atendimento através da orientação de indivíduos e grupos de diferentes segmentos sociais no sentido de identificar recursos e de fazer uso dos mesmos no atendimento e na defesa de seus direitos e encaminhamento de providências, e prestação de orientação social a indivíduos, grupos e à população. Todos os assistentes sociais afirmaram que sim, realizam este tipo de atendimento, mas cinco dos entrevistados colocaram as dificuldades enfrentadas no atendimento. Em resumo, expressaram que este tipo de atendimento é limitado ou muitas vezes precarizado, pois são atendimentos não agendados, isto é, atividades não previstas dentro do rol de atividades diárias do profissional e desta forma precisam ocorrer através do encaixe, durante o intervalo entre um e outro agendamento, ou realizados dentro do tempo limite previsto para outro tipo de agendamento, gerando dificuldades em atender de forma efetiva e com qualidade.

A impossibilidade de atendimento às demandas populacionais de forma qualitativa indica uma concentração do trabalho na produção, inibindo, ou até mesmo suprimindo outras atribuições dos assistentes sociais, como é o caso da realização da visita domiciliar que também foi discutida no questionário como veremos a seguir.

Todos, exceto um participante, informaram que executavam a visita técnica. Todavia, com relação à frequência da realização, foi respondido que às vezes ou raramente elas eram realizadas. Não houve outros comentários sobre o assunto, mas no cotidiano do exercício profissional observa-se que profissionais não conseguem realizar visitas devido ao grande volume de trabalho e baixo número de servidores frente à demanda apresentada, o que dificulta as saídas para serviços externos. Considerando que a visita domiciliar pode qualificar a ação do profissional, atribuindo maiores chances dos usuários terem acesso a serviços e benefícios, limitá-la significa racionalizar, ou seja, controlar os processos para que as demandas institucionais sejam priorizadas em detrimento das necessidades da população que deveria encontrar nas políticas sociais respostas à satisfação de algumas de suas demandas. Entretanto, o que se configura é a tendência apresentada por Raichellis (2009, p. 7): 
No âmbito estatal, o retraimento das funções do Estado e a redução dos gastos vêm contribuindo para o processo de desresponsabilização em relação às políticas sociais universais e o consequente retrocesso na consolidação e expansão dos direitos sociais. Trata-se de uma dinâmica societária que atinge as diferentes profissões, e também o Serviço Social, que tem nas políticas sociais seu campo de intervenção privilegiado.

Os profissionais foram indagados quanto à possibilidade de controlar o tempo ou a duração de seus atendimentos. Sete dos oito assistentes sociais responderam que não possuem este controle, pois seus atendimentos são previamente definidos após estudo de instâncias superiores ligadas às gerências. Logo, todos os assistentes sociais do INSS, em nível nacional, devem se adequar aos padrões definidos pela instituição independente das características de local de trabalho e de possíveis intercorrências.

Com relação às metas institucionais, todos os sujeitos da pesquisa reconhecem que estão submetidos a este tipo de controle e que estas interferem no exercício profissional. Alguns profissionais comentaram a questão através do relato das dificuldades provenientes deste tipo de imposição. Segundo eles, as metas interferem de forma negativa no trabalho devido ao ambiente agressivo que se instaura entre os servidores e pela queda da qualidade dos serviços em detrimento da quantidade.

Ainda sobre o controle institucional, todos os profissionais responderam que reconhecem que seu trabalho é hierarquicamente submetido a modos de controle institucional. Exemplos: monitoramento do tempo de atendimento a cada senha gerada, tempo de espera de cada usuário para ser atendido, quantidade de atendimentos realizados diariamente, fiscalização do cumprimento de metas, organização da agenda de atendimento do profissional e normativas e documentações internas.

Tudo se organiza de forma a diminuir cada vez mais o tempo para cada tarefa e assim estabelecer um padrão a ser aplicado a todos os trabalhadores, permitindo que se faça cada vez mais em menos tempo, independentemente do que isso implica para o trabalhador ou para quem procura o serviço.

Conforme Iamamoto (2008, p. 424), sem considerar as possíveis interferências profissionais decorrentes da competência profissional e da força política, no cotidiano dos profissionais todo esse processo no interior da profissão ocorre devido ao fato de que suas ações são determinadas pelas "condições e relações sociais que circunscrevem esse trabalho" os quais somados a "interferência dos requisitos de produtividade, eficiência, as pressões dos prazos e das rotinas", interferem no trabalho profissional, no seu direcionamento, nas atribuições delegadas, nos recursos autorizados, entre outras dimensões.

Os profissionais foram questionados sobre a contribuição dos sistemas de informação informatizados, os softwares, para a execução do trabalho. Cinco sujeitos responderam que sim, visualizavam uma contribuição, e três responderam que não observaram contribuições. Apesar da reconhecida forma de controle que os softwares exercem sobre o trabalho, apenas um dos profissionais observou este fato reconhecendo que os programas limitam o trabalho em certa medida devido a necessidade de enquadramento de situações complexas em opções padronizadas. $\mathrm{O}$ fato de apenas um profissional perceber o papel disciplinador das tecnologias de informação pode indicar que há uma naturalização desta forma de controle sobre o trabalho, isto é, que os assistentes sociais não vislumbram criticamente a influência negativa que as TI's podem exercer.

De acordo com Santos (1999 apud VELOSO, 2011, p. 64), se por um lado a tecnologia permitiu maior controle sobre a natureza, por outro possibilitou que os seres humanos fossem cada vez mais controlados, levando ao que ele identificou como "intensificação da mecanização do individuo”, o que, em segunda instância, incidiria diretamente no acesso aos direitos, pois "são criadas situações novas para as quais parâmetros de análise e interpretação ainda não foram produzidos”. Em resumo, ainda que as tecnologias de informação tenham possibilitado avanços sem precedentes na história humana, quando apropriadas pela lógica do capital tendem a racionalizar as mais diversas situações inclusive o acesso aos direitos.

\section{Conclusão}

A racionalização é uma necessidade do capital para controlar os processos de trabalho e incrementar a mais valia. No âmbito público, mesmo que tardiamente, a racionalização do trabalho também foi introduzida e tornou-se um meio do Estado para explorar o trabalho dos trabalhadores deste setor. No INSS, isso se tornou mais evidente a partir de 2003, o que acarretou mudanças aos processos de trabalho de todos os trabalhadores da Instituição, inclusive os assistentes sociais.

A partir da pesquisa realizada e da compreensão que o Serviço Social é trabalho, podemos concluir que os assistentes sociais do INSS estão subordinados ao controle dos processos de trabalho assim como os demais trabalhadores. Os profissionais têm o seu trabalho controlado por diversas ferramentas institucionais que limitam a autonomia profissional, tais como: delimitação das agendas dos profissionais (do que atender), do tempo 
disponibilizado para cada atividade, dos sistemas informatizados e da participação na execução e não no planejamento das atividades.

Apesar de evidenciado que os profissionais executam de fato atividades previstas para o Serviço Social nos documentos técnicos institucionais, na maioria das vezes estas estão subordinadas às prioridades definidas pela instituição que dá preferência àquelas que interferem de forma direta nos indicadores e metas estabelecidos pelo INSS.

Desse modo, o que está previsto nos documentos técnicos elaborados pelo Serviço Social e os anseios da própria categoria profissional ficam subordinados aos limites impostos pela instituição, ou seja, àquilo que é permitido ao profissional, pois como qualquer outro trabalhador, o assistente social vendeu sua força de trabalho e preza por sua manutenção em favor de sua sobrevivência.

Por fim, essa nova forma de organização do trabalho adotada pelo INSS, que limita a autonomia do profissional, demonstra dois grandes objetivos: reduzir o número de trabalhadores, ou seja, extrair o máximo de trabalho de uma quantidade reduzida de trabalhadores e assim diminuir cada vez mais os gastos do Estado; e impedir e/ou diminuir o acesso dos trabalhadores aos seus direitos, aos benefícios previdenciários, assistenciais ou de reabilitação profissional. Lembrando que, em ambos os casos, essa redução dos gastos não é para direcionar recursos às necessidades da sociedade e sim para compor o montante à disposição do grande capital. É o Estado mínimo para os trabalhadores e Estado máximo para o capital.

\section{Referências}

BRAGA, L.; CABRAL, M. do S. R. (Orgs.). O Serviço Social na Previdência: trajetória, projetos profissionais e saberes. São Paulo: Cortez, 2008.

BRASIL. Ministério da Previdência Social. Matriz Teórico Metodológica do Serviço Social na Previdência Social. Brasília: MPAS, 1994.

Presidência da República. Lei n 8213 de 24 de Julho de 1991. Dispõe sobre o Plano de Benefícios da Previdência Social. Disponível em: <http://www.planalto.gov.br/ccivil_03/leis/18213cons.htm>. Acesso em: 28 out. 2013.

. Presidência da República. Lei $n^{\circ} 8662$ de 07 de Junho de 1993. Dispõe sobre a profissão do Assistente Social e dá outras providências. Disponível em: <http://www.planalto.gov.br/ccivil_03/leis/18662.htm>. Acesso em: 28 out. 2013.

. Presidência da República. Plano Diretor da Reforma do Estado. Brasília, 1995. Disponível em: <http://www.bresserpereira.org.br/ Documents/MARE/PlanoDiretor/planodiretor.pdf>. Acesso em: 13 nov. 2013.

BRAVERMAN, H. Gerência Científica. In: Trabalho e capital monopolista: a degradação do trabalho no século XX. Rio de Janeiro: Guanabara, 1976. p. 82-111.

DATAPREV, Empresa de Tecnologia e Informação da Previdência Social. A virada da Previdência Social: como acabaram as filas nas portas das agências. Brasília: Dataprev, 2013.

DELGADO, L. B.; AQUINO, I. G. de C. O Mercado (precarizado) de trabalho do Assistente Social em Minas Gerais e no Rio de Janeiro: condições de contratação, remuneração e salários indiretos. In: MOLJO, C. B.; SANTOS, C. M. dos. (Orgs.). Serviço Social e Questão Social: implicações no mundo do trabalho e no exercício profissional do assistente social em Juiz de Fora. Juiz de Fora: UFJF, 2014. p. 93-110.

DIRSAT. Manual técnico do Serviço Social. Brasília: Instituto Nacional do Seguro Social, 2012.

IAMAMOTO, M. V. O Serviço Social na contemporaneidade: trabalho e formação profissional. São Paulo: Cortez, 2001.

. O trabalho do assistente social. In: Serviço Social em tempo de capital fetiche: capital financeiro, trabalho e questão social. São Paulo: Cortez, 2008. p. 414-431.

; CARVALHO, R. de. Relações Sociais e Serviço Social no Brasil: esboço de uma interpretação teórico metodológica. São Paulo:

Cortez, 2005.

MARX, K. O Capital: crítica da economia política. Tradução de Regis Barbosa e Flávio R. Kothe. São Paulo: Nova Cultural, 1996. Livro 1, v.1.

MOREIRA, M. C. O Serviço Social do Instituto Nacional de Seguro Social - INSS a partir da década de 90 - uma análise da implantação da matriz teórico metodológica. 2005. Dissertação (Mestrado em Serviço Social). Faculdade de Serviço Social da Universidade Estadual do Rio de Janeiro. Rio de Janeiro - RJ, 2005.

MOTA, A. E. Cultura da crise e seguridade social: um estudo das tendências da previdência e da assistência social brasileira nos anos 80 e 90. São Paulo: Cortez, 1995.

NETTO, J. P. Capitalismo monopolista e Serviço Social. São Paulo: Cortez, 2005.

PRADO, F. C. de O. Serviço Social na Previdência Social: Racionalização dos processos de trabalho na atualidade. 2014.116. Dissertação de Mestrado (Pós Graduação em Serviço Social e Política Social) - Universidade Estadual de Londrina, Londrina, 2014. RAICHELLIS, R. O trabalho do assistente social na esfera estatal. In: Conselho Federal de Serviço Social. Serviço Social: direitos e competências profissionais. Brasília: CFESS/ABEPSS, 2009. p. 377-391. 
ROZENDO, F. H. da C. O Serviço Social na Previdência Social: a afirmação do seu espaço na materialização dos direitos. 2010. 110. Dissertação (Mestrado em Serviço Social) - Universidade Federal do Rio Grande do Norte, Natal, 2010.

VELOSO, R. Tecnologia e relações sociais. In: Serviço Social, tecnologia da Informação e trabalho. São Paulo: Cortez, 2011. p. 33-69.

YASBECK, M. C. Análise da Matriz Teórico Metodológica do Serviço Social do INSS (1995), considerando a política previdenciária, suas determinações sócio-históricas e o projeto hegemônico do Serviço Social. In: BRAGA, L.; CABRAL, M. do S. R. (Orgs.). $O$ Serviço Social na Previdência: trajetória, projetos profissionais e saberes. São Paulo: Cortez, 2008. p. 115-136.

\section{Notas}

1 É preciso salientar que no Brasil nunca se instituiu um autêntico Estado de Bem-Estar Social como ocorreu nos países de capitalismo central.

2 As ações desta natureza já existiam, mas correspondiam apenas a medidas pontuais e destituídas de qualquer planejamento e organização.

3 No contexto mundial, muitos países sofreram as sequelas da grande crise de 1929. No Brasil, onde o atraso capitalista predominava, a crise empurrou medidas governamentais para modernização das relações capitalistas.

4 Dada a impossibilidade de fazer todo o resgate histórico do Serviço Social na Previdência neste breve artigo, sugerimos para estudos sobre a temática as seguintes referencias: Iamamoto e Carvalho (2005); Braga e Cabral (2008).

5 Há assistentes sociais no INSS que atuam em outras áreas em que não há exigência da formação do Serviço Social.

6 Trata-se de uma atividade em que um servidor do INSS deve receber o pedido do benefício assistencial, BPC. A partir dos documentos apresentados deverá analisar e inserir as informações pessoais e de renda, tanto do requerente quanto de seu grupo familiar, e posteriormente realizar os procedimentos administrativos necessários à continuidade do processo.

7 A avaliação social é uma entrevista realizada com o requerente do benefício ou seu representante legal através da aplicação de um questionário informatizado com vistas a avaliar fatores ambientais, pessoais e de participação, com base nas premissas da Classificação Internacional de Funcionalidade e Incapacidade (CIF) (PRADO, 2014).

8 A Reabilitação Profissional é um serviço destinado aos segurados do INSS que estão incapazes de exercer sua atividade laborativa habitual (por motivo de doença ou acidente) e visa oferecer os meios de reeducação ou readaptação profissional para o seu retorno ao mercado de trabalho. Este serviçoé operacionalizado pelas equipes de Reabilitação Profissional, que podem estar alocadas em cada APS, ou na Gerência Executiva, e neste último caso ela é uma equipe itinerante que se desloca até uma agencia para atendimento aos segurados (PRADO, 2014).

\section{Fernanda C. de Oliveira Prado}

nanda_fco@yahoo.com.br

Mestre em Serviço Social pela Universidade Estadual de Londrina (UEL)

Assistente Social do Instituto Nacional do Seguro Social (INSS)

\section{Instituto Nacional do Seguro Social}

Rua Firman Neto, 201 -Vila São José

Apucarana - Paraná - Brasil

CEP: 86808-020

\section{Evaristo Emigdio Colmán Duarte}

colman@uel.br

Doutor em História pela Universidade Estadual Paulista Júlio de Mesquita Filho (UNESP)

Professor do Serviço Social na Universidade Estadual de Londrina (UEL)

\section{UEL}

Rodovia Celso Garcia Cid, Br 445, Km 380, s/n

Campus Universitário

Londrina - Paraná - Brasil

CEP: 86057-970 